\title{
Evidence for Incremental Validity of Proactive Personality in Predicting Task Performance*
}

\author{
Bharati B. Belwalkar, Jerome J. Tobacyk \\ Louisiana Tech University, Ruston, USA
}

\begin{abstract}
Proactive personality is defined as a dispositional tendency to bring about changes in one's environment. A number of researchers have concluded that proactive personality is an important dispositional construct and that it is distinct from other personality constructs, such as those included in the Big Five (Bateman \& Crant, 1993; Crant, 1995; Thompson, 2005). Literature also suggests that proactive personality is a valid predictor of workplace-specific outcomes like job performance, career success, and leadership quality (Crant \& Bateman, 2000; Crant, 1995; Seibert, Crant, \& Kraimer, 1999; Thompson, 2005). The present research further evaluated the predictive power of proactive personality in relation to task performance. College students $(n=119)$ completed an online survey including measures of proactive personality, task performance, conscientiousness, social desirability, and a brief demographic questionnaire. The results of hierarchical multiple regression indicated that proactive personality is a significant predictor of task performance even when controlling for such empirically-proven strong predictors as conscientiousness and work experience. The authors believe that proactive personality may be a useful dispositional construct for organizational selection and assessment.
\end{abstract}

Keywords: proactive personality, task performance, incremental validity, organization, conscientiousness, social desirability, work experience

\section{Introduction}

The proactive personality construct was introduced by Bateman and Crant (1993) who defined this construct as "a relatively stable tendency to effect environmental change" (p. 107). Since that time proactive personality has emerged as a heuristic construct in organizational settings, showing significant relationships with such variables as job performance, career success, and leadership quality (e.g., Crant \& Bateman, 2000; Crant, 1995; Seibert et al., 1999; Thompson, 2005).

Proactive personality is most frequently measured by Bateman and Crant's (1993) 17-item scale. The internal consistency of this scale ranged from 0.83 to 0.89 across three college student samples. The construct validity of Bateman and Crant's (1993) proactive personality scale was tested in relation to other personality constructs, such as conscientiousness $(r=0.43, p<0.01)$ and social desirability $(r=-0.004$, n.s. $)$. In order to test for criterion validity, Bateman and Crant (1993) correlated their measure with several criteria including, extra-curricular activities aimed at constructive change $(r=0.29, p<0.01)$; personal achievements reflecting

*This research was presented on February 15, 2014 at the Annual Meeting of the Society for Personality and Social Psychology in Austin, TX (USA).

Bharati B. Belwalkar, MS, ABD, Department of Psychology and Behavioral Sciences, Louisiana Tech University.

Jerome J. Tobacyk, Ph.D., Professor, Department of Psychology and Behavioral sciences, Louisiana Tech University. 
change $(r=0.21, p<0.05)$; and peer nominations for transformational leadership $(r=0.33, p<0.01)$ after controlling for social desirability.

Later, Seibert et al. (1999) conducted a study on a sample of 496 employees to understand the predictive value of proactive personality in objective (e.g., pay and promotions) and subjective (e.g., career satisfaction) measures of career success. Seibert et al. (1999) selected ten items with the highest average factor loading from the original 17 -item scale to create a shorter version. Upon shortening the scale to 10 items, inter-item reliability of the scale reduced minimally to 0.86 . Two other short versions of the scale-6-item and 4-item - have also been constructed which demonstrate overlap with Seibert et al.'s (1999) 10-item version. For the purposes of the present study, the original 17-item version was used.

Proactive personality is a widely-researched dispositional construct in the workplace literature (Grant \& Ashford, 2008). Employees with this disposition tend to perceive opportunities for positive changes in the workplace and then actively work to bring about these changes (Bateman \& Crant, 1993; Grant \& Ashford, 2008). Proactive employees demonstrate initiation, perceive their work roles more broadly, take active steps to get work done, initiate changes, follow through until completion, and subsequently perform well at work; hence, proactive personality has been linked to a number of positive work outcomes (see Crant \& Bateman, 2000; Crant, 1995; Seibert et al., 1999; Thompson, 2005), which makes proactive employees desirable to their organizations. Crant (1995) noted that proactive personality is a potentially useful tool for selection due to its strong relationship with job performance, making it a valid predictor.

Several researchers have studied the relationship between proactive personality and performance in various contexts (e.g., Crant, 1995; Grant, Parker, \& Collins, 2009; Seibert et al., 1999; Thompson, 2005), supporting the notion that proactive personality is a significant predictor of job performance. Proactive employees work longer hours and engage in task behaviors more frequently regardless of whether they perceive such behaviors as a part of their formal roles (Bergeron, Schroeder, \& Martinez, 2014). It is likely that supervisors and other employees observe these proactivity-related behaviors and may therefore perceive such employees as better performers. Meta-analytic evidence indicated that proactive personality is significantly and positively related to both subjective performance evaluations (e.g., ratings by peers or by supervisors) and objective performance evaluations (e.g., sales volume, production rate), with stronger relationships typically found between proactive personality and subjective performance measures (Fuller \& Marler, 2009; Thomas, Whitman, \& Viswesvaran, 2010; Tornau \& Frese, 2012). In short, proactive personality showed stronger relationships for subjective compared to objective performance. Additionally, the relationship of proactive personality with job performance depended upon the type of performance assessed; proactive personality was more strongly related to supervisor-rated overall job performance than to either task performance (Fuller \& Marler, 2009) or to any other facets of performance (e.g., sales; Crant, 1995). In the present study, the selected criterion is one of the aspects of overall job performance, namely task performance.

A construct may not be useful if it fails to predict variance in outcomes over and above the variance predicted by other constructs. With this in mind, proactive personality typically explains incremental variance in various outcomes even in the presence of other robust predictors, such as cognitive ability, conscientiousness, work experience, and others (Crant, 1995; Major, Turner, \& Fletcher, 2006; Seibert et al., 1999; Thomas et al., 2010). For example, Crant (1995) reported that proactive personality predicted sales performance above and beyond the sales performance variance predicted by conscientiousness and extraversion. More specifically, 
Crant (1995) showed that proactive personality accounted for an additional 8\% variance in the job performance of 131 real estate agents after controlling for intelligence, conscientiousness, work experience, and social desirability. Moreover, proactive personality also predicted a successful job search after controlling for conscientiousness and self-esteem, which are the key antecedents of this criterion (Brown, Cober, Kane, Levy, \& Shalhoop, 2006). Seibert et al. (1999) controlled for variables that predicted career success (specifically sample demographics and general work motivation) and still found a significant relationship between proactive personality and career success.

However, more recently, studies have revealed contradictory evidence, reporting a lack of incremental validity of proactive personality in predicting criteria (Rodrigues \& Rebelo, 2013; Tornau \& Frese, 2012). Rodrigues and Rebelo (2013) studied proactive personality and the Big Five personality dimensions as predictors of overall job performance (assessed by supervisor ratings) in 95 engineers. They reported a non-significant unique contribution of proactive personality to job performance after the variance accounted for by extraversion, openness, conscientiousness, emotional stability and organizational tenure were extracted. Although an older meta-analysis (Thomas et al., 2010) reported significant validity for proactive personality in predicting job performance over the Big-Five dimensions, a more recent and methodologically robust meta-analysis reported a non-significant contribution of proactive personality over the Big Five (Tornau \& Frese, 2012). Such a discrepancy in the two meta-analytic results might be attributed to the different $k$ sizes of the two studies ( $k$ 's $=103$ and 163 respectively). Moreover, Tornau and Frese (2012) evaluated the methods of performance measurement in their meta-analytic study more analytically than Thomas et al. (2010), which may have resulted in the different conclusions.

Given these past findings about the incremental predictive power of proactive personality, the authors of the present study have attempted to provide additional information about the incremental validity of proactive personality in predicting performance after controlling for conscientiousness, the Big Five dimension that has consistently been one of the best predictors of performance (Barrick \& Mount, 1991; Hunter \& Hunter, 1984). For example, a meta-analysis found that among the Big Five personality dimensions, conscientiousness had the highest validity when predicting job performance (Hurtz \& Donovan, 2000). Results of a study by Neal, Yeo, Koy, and Xiao (2012) examining the Big Five and performance at the individual level show that conscientiousness has a strong relationship with personal performance in the workplace and is a better predictor compared to the other Big Five dimensions. At a group level, consciousness of work team members is a significant predictor of work performance (O’Neil \& Allen, 2011).

Additionally, when inspecting the incremental validity of personality measures, some researchers recommend using a social desirability measure as a control (e.g., Ganster, Hennessey, \& Luthans, 1983; Zerbe \& Paulhus, 1987) whereas others recommend not doing so (e.g., Li \& Bagger, 2006; Moorman \& Podsakoff, 1992; Ones, Viswesvaran, \& Reiss, 1996). It is possible that controlling for social desirability may reduce true variance in some personality constructs (Ones et al., 1996). Although many studies controlling for social desirability have been conducted on the Big Five, very few studies controlling for social desirability have been reported for proactive personality (e.g., Bateman \& Crant, 1993; Crant, 1995). Many of the behaviors associated with proactive personality are socially valued and therefore may be subject to social desirability response bias. Also, in the current study, all of the measures are self-reports which may create a risk of socially desirable responding, subsequently leading to distortion of the obtained results (Nicolson \& Hogan, 1990). Given these considerations, social desirability was used as a control variable in this study. 
Another control variable in the current study was work experience. Hunter and Hunter (1984), in their meta-analytic study, found that work experience had a mean coefficient of almost 0.20 with performance measures. Hence, the present study also controlled for work experience. In the proactive personality literature, to authors' knowledge, only a single study (i.e., Crant, 1995) has tested the incremental validity of proactive personality in predicting work performance over and above social desirability, conscientiousness, and work experience together. In the present study, attempting to partially replicate Crant's (1995) results, the authors hypothesized that proactive personality will show incremental validity over conscientiousness, social desirability, and work experience in predicting task performance (see Figure 1). This hypothesis was tested using hierarchical multiple regression analysis.

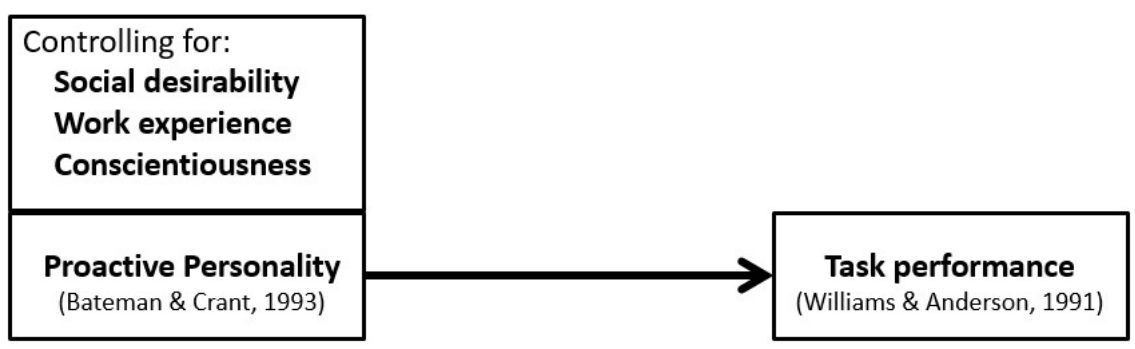

Figure 1. Hypothesized model of proactive personality as a predictor.

\section{Method}

\section{Participants}

A snowball sampling technique was used. Participants $(N=121)$ were primarily recruited from a university in the southern region of United States. Various other sources, such as social networking websites and data collection portals were also used to recruit participants. The inclusion criteria for study participants included minimum age of 18 years and work experience. This study targeted individuals who were currently working or who worked in the past. Participants completed a brief demographic survey (i.e., age gender, ethnicity, number of years of work experience) in addition to the measures (proactive personality, task performance, conscientiousness, social desirability).

\section{Procedure}

The data for this study were collected via online survey using a survey building tool. Participants followed a unique link either sent to them via email or posted on online forums or social networking websites. This web-based format of data collection is comparable to traditional data collection (Gosling, Vazire, Srivastava, \& John, 2004). Participants completed an online survey that included following measures and a brief demographic questionnaire.

\section{Measures ${ }^{1}$}

Proactive Personality (Bateman \& Crant, 1993). This 17-item self-report measure requires participants to rate their agreement with each item on a 7-point rating scale ranging from 1 ("Strongly disagree") to 7 ("Strongly agree"). A sample item is "If I see something I don't like, I fix it". The internal consistency of the scale (Cronbach's alpha) was 0.93 in this study.

\footnotetext{
1 All the measures used in this study have demonstrated satisfactory validity and reliability in the past (please refer to Bateman \& Crant, 1993; Crowne \& Marlow, 1960; Goldberg, 1992; Williams \& Anderson, 1991).
} 
Job-Specific Task Performance (Williams \& Anderson, 1991). Job-specific task proficiency was measured using Williams and Anderson's (1991) 7-item self-report scale of in-role behaviors. The Cronbach's alpha for this scale was 0.81 in the present study. Participants were asked to indicate their level of agreement about how well they perform activities required by their job on a 5-point Likert scale where 1 means "Strongly disagree" and 5 means "Strongly agree". A sample item is "I meet the formal performance requirement of the job".

This scale was selected because it is based on a multidimensional model of job performance proposed by Campbell, McCloy, Oppler, and Sager (1993). The model defines job performance as composed of eight different facets, one of which is job-specific task proficiency. The in-role behaviors scale (Williams \& Anderson, 1991) is analogous to job-specific task proficiency. This scale has been previously used as a self-report measure in some research studies (Jones, 2011; McCook, 2002; Prabhu, 2007). The internal consistency of the scale was above 0.70 for all these studies.

The IPIP Conscientiousness Scale (Goldberg, 1992). Conscientiousness was measured using Goldberg's (1992) International Personality Item Pool (IPIP) measure. The Cronbach's alpha for this 10 -item scale was 0.80. Conscientiousness is one of the Big Five dimensions of personality (Costa \& McCrae, 1988). A sample item is "I pay attention to details". Each scale item was rated on a 5-point rating scale ranging from 1 ("Very inaccurate") to 5 ("Very accurate") according to how accurately it describes oneself.

Social Desirability (Crowne \& Marlow, 1960). A short 8-item version of the Crowne and Marlow (1960) scale of social desirability was included. A sample item was "Are you quick to admit making a mistake?" Participants were required to answer each of the items on a dichotomous scale as either "Yes" or "No". The internal consistency of the short version of this scale was 0.61 which is not high, but is acceptable in research studies. This magnitude reliability is consistent with previously reported studies for younger samples. For example, Beretvas, Meyers, and Leite (2002) reported reliabilities in the $0.50 \mathrm{~s}$.

\section{Results}

Data were collected from 121 participants. One participant did not report gender and race. Table 1 presents demographic data and the inter-correlation matrix among variables. Multivariate outlier analysis, based on centered leverage values and Mahalanobis distances indicated one potential outlier ( $C L V=0.15$; Mahalanobis Dist. $=17.72, p<0.01)$ which was removed. In addition, according to Tabachnick and Fidell's (2013) guidelines for detecting univariate outliers, one of the data points for work experience was a potential outlier with a standardized score above 3.29. Therefore, we removed these two outlying cases from the data before conducting the final analysis, reducing the sample size from 121 to 119 participants. A priori analysis using G*Power 3.1.5 (Faul, Erdfelder, Lang, \& Buchner, 2007) indicated that the required sample size to test this model is roughly 90; therefore; therefore, our sample size of 119 was sufficient. The preliminary analysis indicated that the final data met all the assumptions.

The intercorrelation matrix indicated that there was a significant positive relationship between proactive personality and conscientiousness, $r=0.33, p<0.01$; and, between proactive personality and social desirability, $r=0.19, p<0.05$. These zero-order correlations indicate that higher proactivity is significantly related to both higher conscientiousness and greater social desirability. These correlational results in Table 1 are consistent with Bateman and Crant's (1993) results regarding the relationship between conscientiousness and proactive personality. Results also showed the importance of using social desirability as a control variable — although the proportion of variance shared between proactive personality and social desirability was modest (less than $4 \%$ ). 
The magnitude of the significant positive relationship between proactive personality and conscientiousness raised a suspicion of mutlicollinearity in our regression model. However, the tolerance value and VIF index of less than 5 indicated a lack of multicollinearity (see Stevens, 2002 for a review).

Table 1

Means, Standard Deviations, and Intercorrelations

\begin{tabular}{lllllllll}
\hline Variable & 1 & 2 & 3 & 4 & 5 & $M$ & $S D$ & Alpha \\
\hline 1. Proactive personality & - & $0.33^{* *}$ & 0.13 & $0.19^{*}$ & $0.36^{* *}$ & 89.97 & 15.55 & 0.93 \\
2.Concientiousness & - & 0.17 & $0.24^{* *}$ & $0.60^{* *}$ & 39.80 & 6.33 & 0.80 \\
3. Work experience & & & $0.23^{*}$ & $0.25^{* *}$ & 11.34 & 1.91 & - \\
4. Social desirability & & - & - & $0.20^{*}$ & 17.17 & 3.88 & 0.62 \\
5. Task performance & & & & - & 30.98 & 3.86 & 0.81 \\
\hline
\end{tabular}

Notes. $N=119 ;{ }^{* *} p<0.01,{ }^{*} p<0.05 ; M=$ Sample mean; $S D=$ Standard Deviation; Alpha = Internal Consistency reliability coefficient; Gender $=42 \%$ Males and $76 \%$ Females; Age $(M=43.26$; $S D=13.61)$; Race $=$ Caucasians $(66.2 \%)$ followed by African-Americans (14.3\%), Asians (10.7\%), and Hispanics (4.6\%).

Table 2

Hierarchical Multiple Regression: Proactive Personality as a Predictor of Task Performance after Controlling for Other Predictors

\begin{tabular}{|c|c|c|c|c|c|c|c|c|}
\hline Variable & $R^{2}$ & $F$ & $B$ & $S E$ & $\beta$ & $t$ & $\begin{array}{l}\text { Lower } \\
\mathrm{CI}\end{array}$ & $\begin{array}{l}\text { Upper } \\
\text { CI }\end{array}$ \\
\hline & & & & & & & $95 \%$ & $95 \%$ \\
\hline Step 1 & 0.39 & $24.11^{* *}$ & & & & & & \\
\hline Conscientiousness & & & 2.01 & 0.30 & 0.52 & $6.67^{* *}$ & 1.62 & 2.77 \\
\hline Work experience & & & 0.05 & 0.30 & 0.01 & 0.16 & -0.48 & 0.71 \\
\hline Social desirability & & & 0.56 & 0.30 & 0.14 & 1.85 & -0.02 & 1.20 \\
\hline \multicolumn{9}{|l|}{ Step 2} \\
\hline Proactive personality & 0.41 & $19.83^{* *}$ & 0.67 & 0.31 & 0.17 & $2.16^{*}$ & 0.06 & 1.29 \\
\hline
\end{tabular}

Note. $N=119 ;{ }^{* *} p<0.01,{ }^{*} p<0.05$.

The detailed results of hierarchical multiple regression are presented in Table 2. The overall regression model was significant, $F(4,114)=19.83, p<0.01$. In the first step, conscientiousness, work experience, and social desirability together explained a total of almost $39 \%$ of the variance in task performance, $F(3,115)=$ 24.11; $p<0.01$. In step 2 , proactive personality explained an additional $2.4 \%$ of the variance in task performance over and above the other three variables from step $1, \Delta R^{2}=0.02 ; \Delta F(1,114)=4.28 ; p<0.05$. The examination of regression weights indicated that, in the first step of the regression, only conscientiousness was a statistically significant predictor of task performance, $B=2.01 ; \beta=0.52 ; t(115)=6.67, p<0.01$. In the second step, the regression weight for proactive personality was also statistically significant, $B=0.67 ; \beta=0.17$; $t(115)=2.16, p<0.05$. In other words, proactive personality predicted a statistically significant amount of variance in job-specific task performance in addition to the total variance predicted by conscientiousness, work experience, and social desirability. Therefore, the hypothesis was supported.

\section{Discussion}

Various researchers have previously studied the relationship between proactive personality and performance in various contexts (e.g., Crant, 1995; Grant et al., 2009; Seibert et al., 1999; Thompson, 2005), 
supporting the notion that proactive personality is a significant predictor of job performance. The obtained results similarly demonstrate that proactive personality is a significant predictor of job-specific task performance over and above the combined task performance variance predicted by conscientiousness, social desirability, and work experience. Proactive individuals may take initiative at work, perform tasks diligently, work towards changing things for the better, and may often be perceived favorably by their supervisors and colleagues. Hence, the present study successfully replicated the results of Crant's (1995) study, indicating that proactive personality is a significant predictor of job performance.

However, statistically significant results don't always guarantee practical significance (Gliner, Leech, \& Morgan, 2002). In other words, even though proactive personality explained an additional $2.4 \%$ of variance in job-specific task performance over the other predictors, this modest increment may not be sufficiently large to warrant its use for general selection purposes. It is noted that conscientiousness, by itself, predicted about $36 \%$ of the variance in task performance whereas proactive personality by itself predicted only about $13 \%$ (see Table 1). However, for some professions where employee proactivity could be an added advantage, this construct and its measure may be a valuable selection tool. Some professions which value proactive behaviors (e.g., thinking on one's feet, foreseeing future problems, taking immediate actions), such as first-responders, may find value in the use of proactive personality as a selection tool. It is recommended that organizations seriously consider the use of proactive personality as a predictor in relevant selection settings. Moreover, the authors believe that proactive personality could be a valuable construct not only in workplace but also, more generally, in personal and social life domains. Future research can explore these possibilities.

This study has several limitations. First, there may be a possibility of range restriction in this sample with respect to proactive personality, because the online survey was voluntary and, therefore there is a likelihood that only relatively proactive individuals may have volunteered to complete the survey. Also, some participants in this largely student sample may have had a relatively brief work history mainly emphasizing part time work, resulting in less reliable self-report estimates of performance. The present study may have also suffered from common method bias due to the exclusive use of self-report measures, although caution was taken to control for this potential bias by incorporating a social desirability measure as a control variable in the prediction model. Future research may attempt to replicate and extend this research using objective measures of performance (e.g., sales or number of product units produced). Such a replication would be helpful in extending the generalizability of these findings into real-world settings.

\section{References}

Barrick, M. R., \& Mount, M. K. (1991). The Big Five personality dimensions and job performance: A meta-analysis. Personnel Psychology, 44, 1-26.

Bateman, T. S., \& Crant, M. J. (1993). The proactive component of organizational behavior: A measure and correlates. Journal of Organizational Behavior, 4(2), 103-118. doi: 10.1002/job.4030140202

Beretvas, S. N., Meyers, J. L., \& Leite, W. L. (2002). A reliability generalization study of the Marlowe-Crowne Social Desirability Scale. Educational and Psychological Measurement, 62(4), 570-589.

Bergeron, D. M., Schroeder, T. D., \& Martinez, H. A. (2014). Proactive personality at work: Seeing more to do and doing more? Journal of Business and Psychology, 29(1), 71-86. doi: 10.1007/s10869-013-9298-5

Brown, D. J., Cober, R. T., Kane, K., Levy, P. E., \& Shalhoop, J. (2006). Proactive personality and the successful job search: A field investigation with college graduates. Journal of Applied Psychology, 91(3), 717-726. doi:10.1037/0021-9010.91.3.717

Campbell, J. P., McCloy, R. A., Oppler, S. H., \& Sager, C. E. (1993). A theory of performance. In C. W. Schmitt, \& W. C. A. Borman (Eds.), Personnel selection in organizations (pp. 35-70). San Francisco: Jossey-Bass. 
Chan, D. (2006). Interactive effects of situational judgment effectiveness and proactive personality on work perceptions and work outcomes. Journal of Applied Psychology, 91(2), 475-481. doi: 10.1037/0021-9010.91.2.475

Costa, P. T., Jr., \& McCrae, R. R. (1988). From catalog to classification: Murray's needs and the five-factor model. Journal of Personality and Social Psychology, 55, 258-265.

Crant, M. J. (1995). The proactive personality scale and objective job performance among real estate agents. Journal of Applied Psychology, 80(4), 532-537. doi:10.1037//0021-9010.80.4.532

Crant, M. J. (2000). Proactive behaviors in organizations. Journal of Management, 26(3), 435-462. doi: $10.1177 / 014920630002600304$

Crant, M. J., \& Bateman, T. S. (2000). Charismatic leadership viewed from above: The impact of proactive personality. Journal of Organizational Behavior, 21(1), 63-75. doi: 10.1002/(SICI)1099-1379(200002)21:1<63::AID-JOB8>3.0.CO;2-J

Crowne, D. P., \& Marlowe, D. (1960). A new scale of social desirability independent of psychopathology. Journal of Consulting Psychology, 24(4), 349-354. doi: 10.1037/h0047358

Faul, F., Erdfelder, E., Lang, A. G., \& Buchner, A. (2007). G* Power 3: A flexible statistical power analysis program for the social, behavioral, and biomedical sciences. Behavior Research Methods, 39(2), 175-191.

Fuller, J. B., \& Marler, L. E. (2009). Change driven by nature: A meta-analytic review of the proactive personality literature. Journal of Vocational Behavior, 75(3), 329-345. doi:10.1016/j.jvb.2009.05.008

Ganster, D. C., Hennessey, H. W., \& Luthans, F. (1983). Social desirability response effects: Three alternative models. Academy of Management Journal, 26(2), 321-331.

Gliner, J. A., Leech, N. L., \& Morgan, G. A. (2002). Problems with null hypothesis significance testing (NHST): What do the textbooks say? The Journal of Experimental Education, 71(1), 83-92.

Goldberg, L. R. (1992). The development of markers for the Big-Five factor structure. Psychological Assessment, 4(1), 26-42. doi: 10.1037/1040-3590.4.1.26

Gosling, S. D., Vazire, S., Srivastava, S., \& John, O. P. (2004). Should we trust web-based studies? A comparative analysis of six preconceptions about internet questionnaires. American Psychologist, 59(2), 93-104. doi:10.1037/0003-066X.59.2.93.

Grant, A. M., \& Ashford, S. J. (2008). The dynamics of proactivity at work. Research in Organizational Behavior, 28 , 3-34. doi:10.1016/j.riob.2008.04.002

Grant, A. M., Parker, S., \& Collins, C. (2009). Getting credit for proactive behavior: Supervisor reactions depend on what you value and how you feel. Personnel Psychology, 62(1), 31-55.

Hunter, J. E., \& Hunter, R. F. (1984). Validity and utility of alternative predictors of job performance. Psychological Bulletin, 96(1), 72-98. doi:10.1037/0033-2909.96.1.72

Hurtz, G. M., \& Donovan, J. J. (2000). Personality and job performance: The big five revisited. Journal of Applied Psychology, 85, 869-879. doi:10.1037/0021-9010.85.6.869

Jones, K. S. (2011). "I'm Too Good to Be Bad": The moderating role of honesty-humility in aggressive and prosocial reactions to first and third party unfairness (Master's Thesis). Retrieved from https://www.ideals.illinois.edu/bitstream/handle/2142/24195/Jones_Kisha.pdf.

Li, A., \& Bagger, J. (2006). Using the BIDR to distinguish the effects of impression management and self-deception on the criterion validity of personality measures: A meta-analysis. International Journal of Selection and Assessment, 14(2), 131-141. doi:10.1111/j.1468-2389.2006.00339.x

McCook, K. D. (2002). Organizational perceptions and their relationships to job attitudes, effort, performance, and organizational citizenship behaviors (Doctoral dissertation). Retrieved from http://www.latech.edu/library/dbs/diss.html

Major, D. A., Turner, J. E., \& Fletcher, T. D. (2006). Linking proactive personality and the Big Five to motivation to learn and development activity. Journal of Applied Psychology, 91(4), 427-935. doi: 10.1037/0021-9010.91.4.927

Moorman, R. H., \& Podsakoff, P. M. (1992). A meta-analytic review and empirical test of the potential confounding effects of social desirability response sets in organizational behavior research. Journal of Occupational and Organizational Psychology, 65(2), 131-149.

Neal, A., Yeo, G., Koy, A., \& Xiao, T. (2012). Predicting the form and direction of work role performance from the Big 5 model of personality traits. Journal of Organizational Behavior, 33, 175-192.

Nicolson, R. A., \& Hogan, R. (1990). The construct of social desirability. American Psychologist, 45(2), 290-292. doi: 10.1037/0003-066X.45.2.290

O’Neil, T. A., \& Allen, N. J. (2011). Personality and the prediction of team performance. European Journal of Personality, 25, $31-42$. 
Ones, D. S., Viswesvaran, C., \& Reiss, A. D. (1996). Role of social desirability in personality testing for personnel selection: The red herring. Journal of Applied Psychology, 81(6), 660-679. doi:10.1037/0021-9010.81.6.660

Prabhu, V. P. (2007). Understanding the effect of proactive personality on job related outcomes in an organizational change setting (Doctoral dissertation, Auburn $\quad$ University). $\quad$ Retrieved from http://etd.auburn.edu/etd/bitstream/handle/10415/935/PRABHU_VEENA_58.pdf

Rodrigues, N., \& Rebelo, T. (2013). Incremental validity of proactive personality over the Big Five for predicting job performance of software engineers in an innovative context. Revista de Psicología del Trabajo y de las Organizaciones, 29(1), 21-27.

Seibert, S. E., Crant, M. J., \& Kraimer, M. L. (1999). A longitudinal model linking personality and career outcomes. Journal of Applied Psychology, 84(3), 416-427.

Stevens, J. (2002). Applied multivariate statistics for the social sciences. Mahwah, N.J: Lawrence Erlbaum Associates.

Tabachnick, B. G., \& Fidell, L. S. (2013). Using multivariate statistics (6th ed.). Boston: Allyn \& Bacon.

Thomas, J. P., Whitman, D. S., \& Viswesvaran, C. (2010). Employee proactivity in organizations: A comparative meta-analysis of emergent proactive constructs. Journal of Occupational and Organizational Psychology, 83(2), 275-300. doi: 10.1348/096317910XS02359

Thompson, J. A. (2005). Proactive personality and job performance: A social capital perspective. Journal of Applied Psychology, 90(5), 1011-1017. doi: 10.1037/0021-9010.90.5.1011

Tornau, K., \& Frese, M. (2012). Construct clean-up in proactivity research: A meta-analysis on the nomological net of work-related proactivity concepts and their incremental validities. Applied Psychology: An International Review, 62(1), 44-97. doi: 10.1111/j.1464-0597.2012.00514.x

Williams, L. J., \& Anderson, S. E. (1991). Job satisfaction and organizational commitment as predictors of organizational citizenship and in-role behaviors. Journal of Management, 17, 601-617.

Worthington, R. L., \& Whittaker, T. A. (2007). Scale development research: A content analysis and recommendations for best practices. The Counseling Psychologist, 34(6), 806-838. doi: 10.1177/0011000006288127

Zerbe, W. J., \& Paulhus, D. L. (1987). Socially desirable responding in organizational behavior: A reconception. Academy of Management Review, 12(2), 250-264. doi:10.2307/258533 